\title{
SELECTED ASPECTS OF CBRN PROTECTION IN MILITARY PEACE SUPPORT OPERATIONS
}

\author{
Witalis PELLOWSKI*, Marian ŻUBER*, Mirosław SMOLAREK**, \\ Mikołaj KUGLER* \\ *Military University of Land Forces, Wroclaw, Poland \\ ** Baltic Defence College, Tartu, Estonia \\ witalis.pellowski@awl.edu.pl
}

\begin{abstract}
This paper presents the results of studies based on the analysis of field exercises organized for the purpose of disinfection of preventive sub-units regrouping from the areas threatened with endemic infectious diseases. The research also concerns the analysis of the possibility of conducting the liquidation of contamination in the conditions of access to the local infrastructure with the use of chemical weapons equipment and cooperation with the non-military system: police, fire brigade, emergency medical services and municipal guards. The method of preparation of the ozone chamber in field conditions is also presented.
\end{abstract}

Keywords: peace support operations, decontamination, risk management, CBRN

\section{Introduction}

Military peace support operations are conducted in different regions in the world, where there may be a whole variety of CBRN threats. In the event that troops and civilian auxiliary staff have performed tasks in the areas possibly affected by various endemic diseases, there is a risk that these diseases will be transferred with the personnel when returning home. There is then a need to identify contaminations and estimate the risks associated with the relocation of threats as well as the organization of preventive activities. Following risk analysis, decontamination should be prepared and effectively performed.

\section{Estimating the risk of contamination}

For the purpose of risk analysis five-step risk matrix is used, where it is significant to correctly identify the category or categories of probabilities of potential losses in relation to the scale of threat scenarios analyzed.

Risk Matrix Method uses two main factors affecting the value of the risk determined:

- the likely occurrence of a risk (specific scenario);

- the effects (consequences) of such a risk (specific scenario).

These factors are graded on an arbitrary scale and the ones closest to reality are selected.

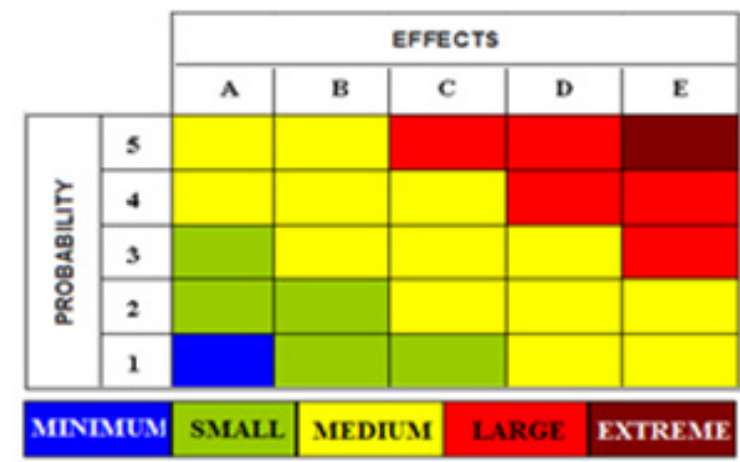

Figure 1: A graphic illustration of risk matrix [1] 
scale is shown below.

Table 1 A description of the probability scale [2]

\begin{tabular}{|c|l|l|}
\hline SCALE & PROBABILITY & \multicolumn{1}{c|}{ DESCRIPTION } \\
\hline 1 & very rare & $\begin{array}{l}\text { It may occur only in exceptional circumstances. It may } \\
\text { occur once in five hundred or more years. }\end{array}$ \\
\hline 2 & rare & $\begin{array}{l}\text { It is not expected that it will happen and/or is not at all } \\
\text { documented in human communications and/or events have } \\
\text { not occurred in similar organizations, equipment and } \\
\text { communities and/or there is little chance, reason or other } \\
\text { circumstances suggesting that events can occur. They may } \\
\text { occur once in one hundred years. }\end{array}$ \\
\hline 3 & possible & $\begin{array}{l}\text { It may happen at a certain time and/or they are no or rarely } \\
\text { accidental events that are documented or partially } \\
\text { transmitted orally and/or very few events and/or there is a } \\
\text { chance, reason or device making it possible to happen. It } \\
\text { may happen once in twenty years. }\end{array}$ \\
\hline 4 & probable & $\begin{array}{l}\text { It is likely to occur in most circumstances and/or such } \\
\text { events are systematically recorded and transmitted orally } \\
\text { and/or there is a good chance, reason or devices allowing it } \\
\text { to happen. It may happen once in five years. }\end{array}$ \\
\hline 5 & very likely & $\begin{array}{l}\text { It is expected that it will happen in most circumstances } \\
\text { and/or such events are very well documented and/or } \\
\text { function among people and are transmitted orally. It may } \\
\text { happen once a year or more frequently. }\end{array}$ \\
\hline
\end{tabular}

The employment of chemical troops to perform complex tasks related to carrying out the elimination of the effects of biological hazards poses a major challenge for commands and staffs with respect to its organization. Implementation of tasks under the conditions forced by an emergency (crisis) situation is associated with numerous aspects of risk calculation [3]. Available research and analyzes show that it will be time. This factor has its direct implications in the form of biological effects (e.g. the impact of biological material on living organisms) or degradation of the natural environment (after the release of toxic post-process solutions). The presence of biological contamination usually "necessitates" the organization and implementation of preventive decontamination activities. Their effectiveness is determined mainly by time as the overriding factor of the effectiveness of operations. Other factors, such as the type of contamination method proposed or the selection of decontamination means, are obviously absolutely significant, but on the basis of knowledge and experience as well as normative documents, they are selected depending on the situation. The best way to manage risk is to optimally use the assumptions, by implementing the algorithm presented in Figure 2. Nowadays, the instability of external conditions requires that all the determinants are precisely specified, as the relationships between them can have serious consequences. The risk related to rescue operations is encumbered with many threats to people and the environment. They require special care on the part of those ones responsible for planning and directing activities. 


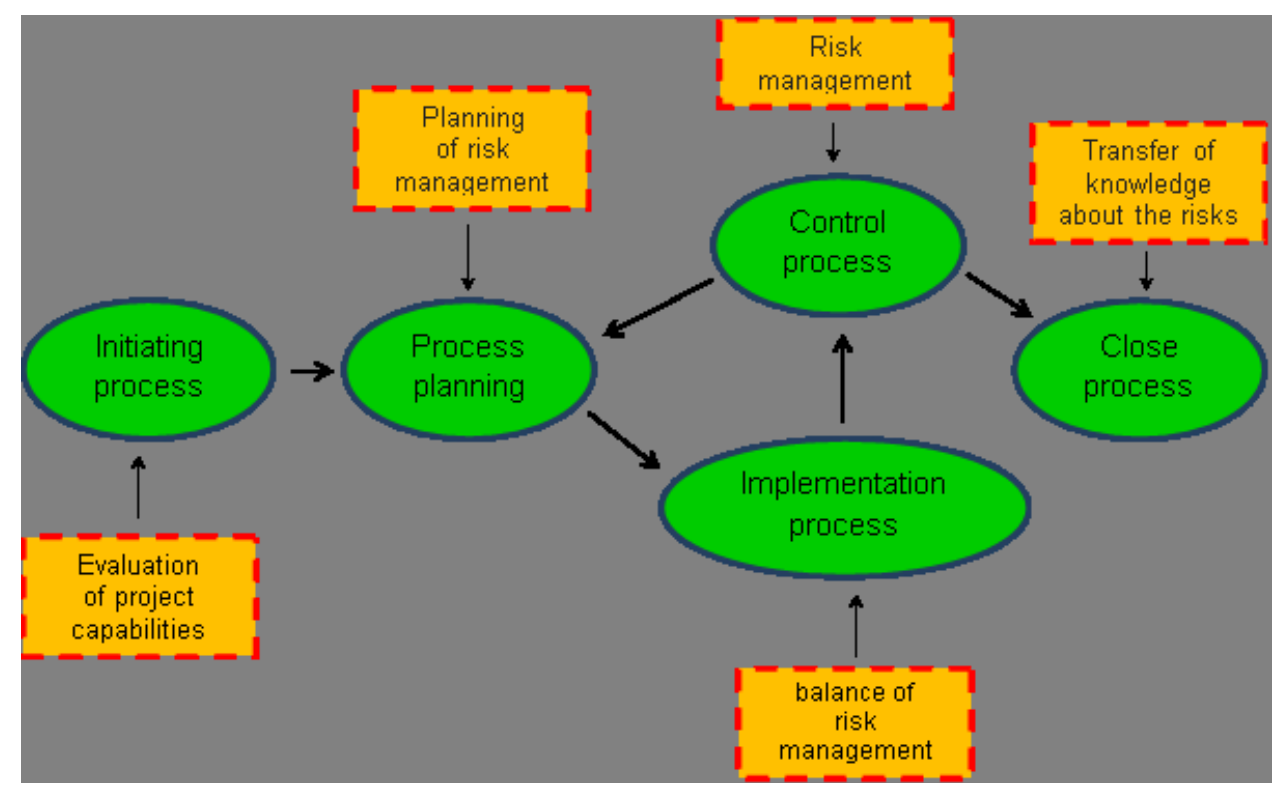

Figure 2: Risk management algorithm according to Pellowski, Skorupka [2]

Regan S. [4] in his publication focused on the problem description of risk analysis. He described it as an overview of the inputs and outputs of the risk management and risk assessment of the likely impact of the project. In his view, a good analysis is based on the supported database archives and current information. The analysis should be commented on by a design and planning team, taking account of the targets. When analyzing the risk, all potential risk factors that may affect the performance of the task should be considered.

Sienkiewicz P. in the monograph [5] described the concept of risk as a bonding layer between the probability of failure and the expected losses or benefits. Moreover, he argues that "you can meet with different varieties of risk, for example:

- the likely risks, such as the risks associated with the operation of random factors that cannot be taken into account in every action, and therefore operates with the values of average interest to us,

- situational risk - characteristic of a complex situation in the absence of violent conflict and sensible prevention (for example in the struggle with nature),
- operational risk, an acute conflict, i.e. when we are one of the parties to achieve the opposite (conflicting) objectives".

Safe risk management is warranted by the appropriate monitoring of numerous diverse and complex factors conditioning the scope of work aimed at the identification and ongoing assessment of uncertainties and risks.

Risk monitoring should identify the supervision of the proper implementation of the variant (strategy) action, namely to control the direction of the intended results, and not to control. Furthermore, it is an important element of strategic, operational and tactical (current) risk management. Risk monitoring is to [6]:

- review risk types and span for the moment on a regular basis,

- control and order an information flow in order to determine sources of error in the use of the previously developed evaluation of the effectiveness of air forces, including risk measurement formulas,

- assess any differences between the objectives of the action plan and the actual results.

It should be kept in mind that the idea of the possibility of controlling uncertainty 
encourages leaders to take risks which they previously avoided. Thus, the ability to monitor risks can sometimes pose new risks for the planned activities. As a result, the number of risks may be increasing, but their effects are less harmful to the accomplishment of tasks. Risk monitoring in terms of the verification of opportunities to obtain benefits or the risk of incurring losses. Therefore, information on irregularities, mainly risk factors that should be generated within the organization (specialized units) implementing planned activities. General assumptions and risk management procedures are shown in Figure 3.

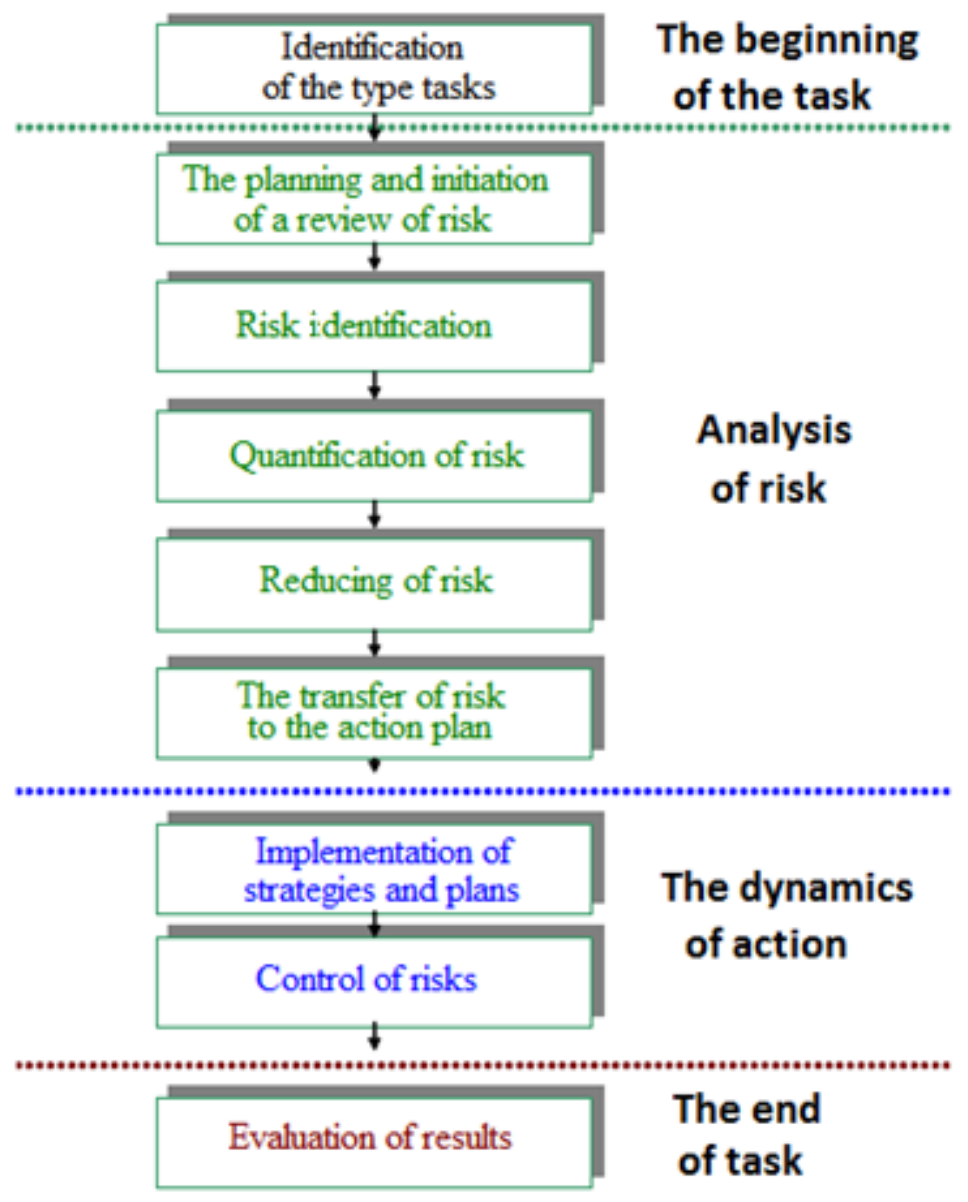

Figure 3: Risk management procedure according to Pellowski, Skorupka [2]

\section{Decontamination of people and their equipment}

The main goal of eliminating contamination is to reduce losses in people caused by the effects of biological substances. Decontamination of people consists in:

- washing and/or rubbing the exposed or contaminated parts of body with damp towels, gloves or sponges soaked in a washing, disabling or water solution,
- removal of contaminated clothing, - using a substitute garment.

The decontamination of personal equipment and equipment consists in the use of:

- mists from a germicidal solution, - ozone originating from a generator,

- disinfectant solutions applied to contaminated surfaces and then their removal [7]. 


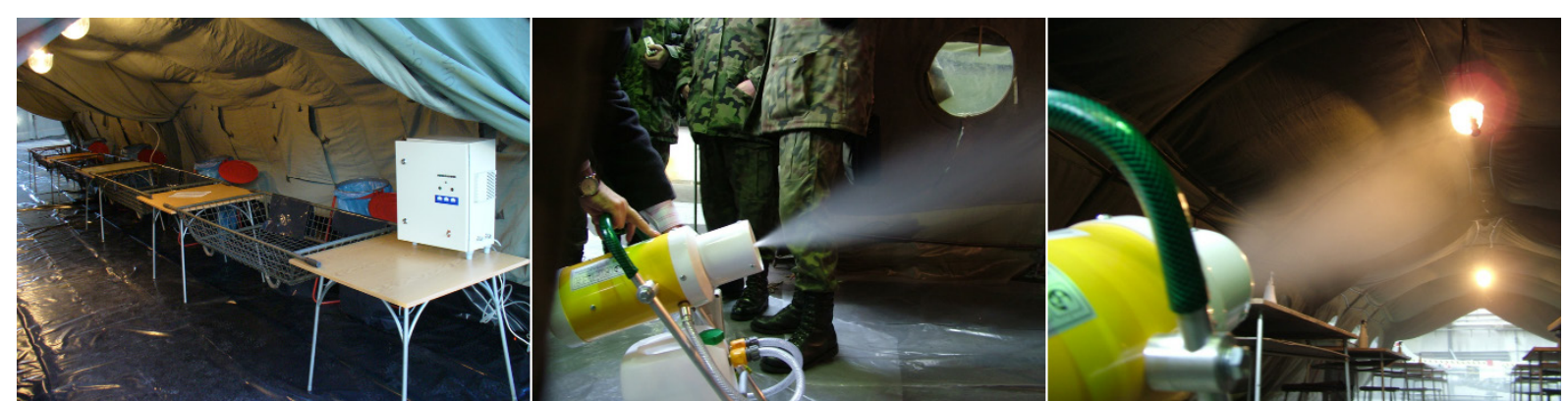

Figure 4: From left an ozone chamber with a generator - a disinfection fogger (courtesy of Niewitowski B.)

Ozone $\left(\mathrm{O}_{3}\right)$ is used in ozone chambers (Figure 4), owing to which it permeates even the smallest pores and slits of textiles, cleaning and disinfecting very effectively. The ozone chamber allows the use of innovative technology where, due to the sensitivity of materials or for other reasons, traditional disinfectants and bacteria eliminating agents cannot be used. No possibility of effective cleaning and cleaning with the traditional method increase the legitimacy of using the ozone chamber.

The advantages of fogging equipment:

- versatility of use (disinfection, disinfestation and deodorization);

- significant saving of time and preparation for fogging (up to $60 \%$ compared to traditional spraying);

- the possibility of using a wide range of fogging disinfectants;

- smooth regulation of the mist flow;

- excellent mist quality due to the use of special dispersion heads;

- limitation of human contact with fogging agents (safe disinfection and disinfestation) due to the possibility of fogger operation without personnel supervision;

- reduction of odour nuisance to the environment and neighborhood (effective deodorization);

- adjustment of the working nozzle angle;
- high efficiency due to excellent mist quality (average droplet thickness 5 $10 \mu \mathrm{m})$ produced by a strong air stream, subject to additional turbulence.

\section{Conclusions}

The performance of tasks in Peace Support Operations carries the risks associated with the displacement of biological threats. Each organizational undertaking requires a thorough risk analysis. This is a key element in avoiding unnecessary threats. The proposed risk estimation algorithm is a significant element of the decision-making process when dealing with contamination.

An important element in preventing the spread of contaminants is proper risk assessment and effective preventive disinfection. Applied ozonation technology allows for almost complete reduction of waste solutions. This is important from the point of view of protection against secondary contamination. Well-prepared and perfectly disinfected people and their equipment can stop or prevent outbreaks.

\section{Acknowledgements}

This article has been developed as part of scientific and research project No. $100 / \mathrm{WNoB} / 39 / \mathrm{DzS}$, partially financed from the funds of the Ministry of Science and Higher Education of the Republic of Poland.

\section{References}

[1] http://rcb.gov.pl/wp-content/uploads/KPZK-cz.1.pdf

[2] Abgarowicz G. Risk analysis for crisis management, CNBOP-PIB Józefów, 2015286 
[3] Pellowski W., Skorupka D., The Journal of Science of the Gen. Tadeusz Kosciuszko Military Academy of Land Forces, Vol. 145, No 3, pp. 68-78, 2007.

[4] Regan S., Risk, Uncertainty and Profit, University of Boston Press, 1921, 83.

[5] Sienkiewicz, P., Analysis System - Fundamentals and Applications, Bellona Warszawa, 1994, 137.

[6] Ostrowska E., Risk investment projects, PWN Warszawa, 2002, 86.

[7] Pellowski W., Machaj D., Scientific works of the Academy Jan Dlugosz in Czestochowa. Technology, Information Technology, Security Engineering, No. 1, s. 371-386, 2013. 